\title{
Incorporation of Product Approach and Process Approach in English Writing Instruction
}

\author{
Jian Guan \\ School of Foreign Languages, Jilin Agricultural University, Changchun, Jilin 130118 \\ hunter2011@foxmail.com
}

Keywords: Process approach, Product approach, Incorporation.

\begin{abstract}
In this paper, the author first makes a brief review of writing instruction development. Then she introduces the two kinds of writing instruction approaches: product approach and process approach. In Chapter Two, the author makes a detailed comparison of these two approaches based on data and information from research on current English writing teaching. By comparison, the author finds that both approaches have their advantages and disadvantages: the advantages of product approach lie in the fact that, according to cognitive psychology theory, some aspects of this approach such as imitation and drills and practice comply with learners, acquisition procedure, and as is proved by real classroom teaching, it can of certain help to improve students, writing ability.
\end{abstract}

\section{Introduction}

As is known to all, the minimum score of composition in CET-4 has been set up at Score 6 since 1997. That is to say, to pass CET-4, not only do students have to get a total score of or higher than 60 , but their composition should score at least 6 points. They must satisfy these two standards at the same time. Although this has somewhat aroused students' attention in writing, and their score in composition is improving, as we can see from Chart 1, the rate of improvement is rather slow. And from Chart 2 and Chart 3, we can see neither teachers nor students attach sufficient importance to writing.

Then how to deal with this problem? We may find a solution from the relationship between language and mental thinking. The nature of writing is mental thinking. Language is merely the clothes or carrier of thoughts. But the traditionally dominating product approach fails to grasp the essence of writing and both teachers and students under this approach pay all their attention to such superficial stuff as grammar, spelling etc. That's why we have the complaints above. Then it seems advisable and natural to turn to process approach. Under this approach, writing is divided into several procedures and by doing so the difficulty of writing is lessened. In addition, students' enthusiasm is brought into pull play because one of the important factors of this approach is peer cooperation. However, the advent of process approach makes many teachers totally discard product approach. This is to go from one extreme to another in my opinion. Product approach does have various weaknesses. However, if we discard it totally, we will be throwing the baby out of the bath water. Thoughts and language are interrelated and interdependent. They are both the components of writing. And comparatively speaking, thoughts are more important but this does not mean language should be ignored. Thus, while we lay emphasis on writing process or thoughts, we should also pay attention to some useful aspects in product approach which could be retained and continue to be used in English writing instruction. To sum up, product approach and process approach should be incorporated to serve current writing instruction jointly.

\section{The Status Quo and the Existing Problems of Current Writing Instruction in China}

From the perspective of students, the typical problems and difficulties encountered by EFL/ESL students of writing are as follows: (1) Students' ability is poor in laying out the whole composition, which is in most cases due to the somewhat disordered mental thinking and a lack of logic;(2) The passages are void of contents and substance; (3) Grammar mistakes are various and repeated again and again; (4) Students' mental thinking scope is narrow and they, more often than not, fail to 
explore the topic widely and in an in-depth way. (5) Combined with the frequently limited and unconstructive, sometimes negative and often purely grammatically focused nature of teacher feedback on the completed piece of writing, students' lack of interest and enthusiasm in writing contributes to a strong lack of student motivation and a distinct reluctance to complete writing assignments either inside or outside the classroom. (6) Students do not respond to the evaluation properly. Most of the students only have a glimpse of the grades when the composition is returned to them after being evaluated by teachers and then put them aside. No revising work or rethinking work is conducted about the composition. As a result, they do not make any progress in writing, which in turn dampens their interest and enthusiasm in learning writing. And it forms a vicious cycle. (7) Chinglish and traces of Chinese way of thinking permeate some of the students' compositions. (8) To produce different varieties of acceptable written texts, EFL students may also encounter problems arising from their unfamiliarity with the conventions of various genres of written English. (9) The covert nature of written discourse, whereby distance from the reader obliges the writer "to make inferences about the relevant knowledge possessed by the reader, and decide what to include and what to omit from their text", may constitute a further obstacle to the already daunted EFL-student writer. This particular obstacle can be compounded by the frequent lack of any clear purpose or audience for writing resulting from the artificial nature of many EFL writing assignments and the lack of attention paid to the relevant issues of discourse and genre in the traditional, largely syntax-focused classroom. (10) Finally, the students' task in completing a writing assignment is made still more difficult by the lack of provision for practice of the writing skill in class since writing often becomes a low priority for the teacher when time and syllabus constraints come to the fore. Generally speaking, students' poor performance in writing can be attributed to their poor cognitive ability, mental thinking ability and observatory ability as well as their lack in the accumulation of life experience and their insufficient amount of reading and writing practice. (Ma Guanghui, Wen Qiufang, 1999) .

\section{Some Suggestions for Incorporating These Two Approaches}

From the above analysis, we can arrive at the conclusion that product approach should not be vehemently criticized and discarded. Although it has its own particular limitations and disadvantages, product approach does not lose its life and effect in writing teaching and still has the value of being drawn upon. Some aspects and advantages of product approach can be maintained and incorporated into process approach to solve the problems jointly. The use of drills and practice and model compositions are two cases in point.

Drills and Practice. Drills and practice is an important aspect in product approach. Some people in favor of product approach hold the view that good composition results from practice. They believe that the more you practice, the better you write. Although it is not $100 \%$ correct, it does make sense. Writing is a skill and theoretically speaking, the more one practices, the better he/she writes. The improvement of writing skills and abilities require practice and every link of writing cannot be alienated from practice. Writing is like swimming; one cannot swim if he/she does not dive into the water and practice it by himself/herself. Imagine teachers telling students much knowledge and many techniques and theories of writing. If students do not practice it and apply what they have been taught into practice, how can their writing ability be improved? In that case, although students know much about writing skills and strategies, they are no more than an armchair strategist. So practice and drill is an indispensable part and link in the chain of English writing.

One way of practice is keeping diary or journal in English. It exerts no restriction on the topic and students can air their views freely. Another way is to lift the restriction of topic and give students much freedom to convey what they want to way, i.e. to provide students with more than one topic for them to choose from or totally lift the restriction of topic. However, the connotation here of practice should be expanded. It is no longer limited to practice about words, phrases, grammar etc; it should be expanded to include practice about such macro aspects as structuring of the whole essay, readers, brainstorming, focusing and evaluation etc. By doing so teachers can 
incorporate the two differently-focused teaching approaches effectively and students may feel writing to be something improvable and less difficult.

Model Composition. Presenting students with model compositions is another alternative. Under product approach, teachers follow the procedure of presenting model composition, explaining and analyzing it and asking students to copy it or imitate it. Writing here can be compared to drawing and the first step is to imitate those vintage works. By imitating a model composition, students' language competence will greatly improve. What's more, the use of model composition can be explored in an in-depth way. Students can absorb a wealth of writing techniques and essences, such as the strategy of laying out the structure of an essay, the skill of creating cohesion, different stylistic features of different genres and their respective writing methods, so that they can learn to apply them to their writing flexibly. It enables students to have a command of writing of all different styles and genres in a short time and overcomes the weakness of time-consuming and sometimes poor effect of process approach. Apart from that, imitating is also the basis of innovation. After imitating, analyzing, absorbing and digesting abundantly, students can sometimes form their own style and begin to innovate.

Then what do teachers have to do with model compositions? First, teachers should take care in choosing model compositions and the ones they choose should correspond with students' present English level and are easy for them to absorb. Second, teachers should navigate students in using these model compositions. They should not only focus on the micro aspects of the composition such as language usage, but also explore the macro aspects of writing such as structure and genre. And sometimes, different model compositions on the same topic should be chosen and put together for students to make comparison. By comparison students will have a consolidated understanding of the versatile nature that is writing and it will facilitate their acquisition of language skills. Apart from that, some minor skills in making use of model compositions should be taught to students. Teachers can guide them to conduct intensive reading and make notes while reading. Teachers can analyze some important aspects of a model essay and they can also guide students to conduct self-appreciation and group discussion. After that, teachers can check students' appreciation by holding report conference.

\section{Conclusion}

Writing instruction research is a formidable task. It requires teachers to have expansive knowledge such as classical rhetoric, syntax, semantics, discourse, cognitive psychology and so on since writing is not a single discipline but a hybrid of disciplines. It is also a practical discipline. Thus it needs teachers to organize the classroom efficiently, especially through peer cooperation, conferencing or debates and other procedures so that students can really benefit from it. If writing teachers can, after examining the problems they are facing, come to realize the importance of incorporating different theories and strategies, our research on writing instruction approach will surely become more fruitful and rewarding.

\section{References}

[1] Aristotle. Rhetoric. trans. W. Rhys Roberts, Random House, Inc., 1954.

[2] Barbara E. Walvoord. Three Steps to Revising Your Writing, Library of Congress Cataloguing-in-Publication Data, 1992.

[3] Bazerman, Charles. “A Relationship between Reading and Writing: The Conversational Model”. College English, Vol. 41 (1980): 656-661.

[4] Brown, G. et al. Discourse Analysis, Cambridge: Cambridge University Press.1983.

[5]Campbell, George. Philosophy of Rhetoric ed. Lloyd F. Bitzer Carbondale: 
Southern Illinois University Press, 1963. 
